j. port. sci. res.
ISSN: 2616-7441 (Online)
ISSN: 2616-6232 (Print)
ISSN: 2616-7220 (USB)

\title{
Endometrial biopsy is an important diagnostic tool for the evaluation of abnormal uterine bleeding
}

\author{
J. Makki*1, A. H. Al Khafaj ${ }^{2}$ \\ ${ }^{1 \& 2}$ College of Dentist, Uruk University. Baghdad, Iraq.
}

jaafer58@hotmail.com

\begin{abstract}
In this study 100 biopsies were taken from the endometrium of childbearing women (18-50 yrs. of age) suffering from abnormal vaginal bleeding from Jan 2019-Dec 2019. Endometrial Biopsy (EB) is safe, an outpatient procedure, low cost, carries out without general anesthesia \& the incidence of hemorrhage, infection \& uterine perforation are less common than with D\&C. EB is an alternative to dilatation \& curette $(\mathrm{D} \& \mathrm{C})$ for the evaluation of infertile \& abnormal vaginal bleeding or dysmenorrheic patients. There are two main groups of causes to irregular vaginal bleeding. 1. Organic disease ( $74 \%$ of the cases), in this group there are obvious lesion such as, endometrial polyp, endometrial hyperplasia \& chronic endometritis. The most common cause was endometrial hyperplasia $48 \%$, it is commonly seen during the perimenopausal period (40-50yr). Less common causes include chronic endometritis $8 \%$, hydatidiform mole $7 \%$, and endometrial polyp 7\%. 2. non-organic disease comprises $19 \%$ of all cases, anovulatory period $13 \%$ or Luteal phase insufficiency $6 \%$. They are commonly seen from age of $18-40 \mathrm{yrs} .6 \%$ of the cases found to have normal endometrium. 5 endometrial biopsies were inadequate $\&$ unsatisfactory for histopathological interpretation. The aim of this study is to evaluate the usefulness \& disadvantages of EB \& to compare it with the traditional method of endometrial curette.
\end{abstract}

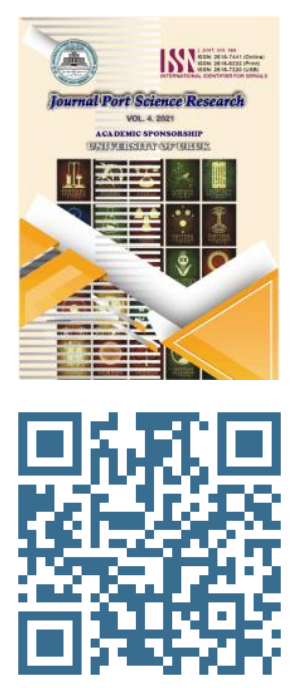

Crossref

$10.36371 /$ port.2021.5

Keywords: Endometrial, diagnostic, abnormal, Vitexin.

\section{INTRODUCTION}

Previously tissue from the endometrium taken for diagnostic purposes has been obtained by dilatation of the cervical canal and curettage of the endometrial cavity (D\&C), carried out under general anesthesia. It has been regarded for a long time as the method of choice for the detection and diagnosing of endometrial lesions especially the localized lesions, such as endometrial polyps and carcinoma. Regeneration of the endometrium proceeds very rapidly after curettage. Complete restoration occurs in 2 or 3 days in most instances. Rarely, intrauterine adhesions can develop, leading in to amenorrhea $\&$ other menstrual abnormalities [1].

Endometrial biopsy is a good alternative way for studying the pathological changes of the endometrium, it is cheap, simple, without any complications \& does not need general anesthesia [2].

It provides only a sample of endometrium, so small area of abnormal endometrium such as polyps, \& submucosal myoma may be missed [3].

Endometrial biopsy is a safe alternative to $\mathrm{D} \& \mathrm{C}$ for the evaluation of infertile \& abnormal vaginal bleeding or dysmenorrheic patients. 1
At present, this procedure (as carried out with various suction devices) has become the method of choice for the initial approach to patients with suspected endometrial lesions [3]. An adequate clinical history from the patient, is necessary for the examiner pathologist to evaluate the biopsies, history including

Patient age, menstrual history, parity, any history on using of exogenous hormones or tamoxifen, \& any previous endometrial disorder [4].

Abnormal uterine bleedings are either the result of an identifiable organic diseases, or bleeding not associated with an organic cause known as dysfunctional uterine bleeding.

Most common organic diseases causing vaginal bleeding include;

1) Chronic endometritis; - Plasma cells are the most useful diagnostic criteria, other morphological features include a disturbance in maturation-for example, focal areas that are out of cycle with other areas of stromal oedema $\&$, a spindle-cell alteration of the stroma, especially around glands [5].

2) Endometrial polyps; - In most of the cases the gynecologists are not aware of the presence of a polyp. In such instances, fragments of polyp are admixed with normal endometrium making the diagnosis difficult, as 
the features can be subtle. When a biopsy is carried out for abnormal uterine bleeding, the pathologist should always consider the possibility of a polyp. Main morphological features suggesting the presence of polyp are fibrous stroma \& collections of thick-walled stromal blood vessels, glandular architectural abnormality and various epithelial metaplasia.

ENDOMETRIAL HYPERPLASIA: It classified into simple and complex forms depending on the glandular architecture. The endometrium shows proliferative glands, cystically dilated of irregular sizes and shapes, with focal outpouchings, infoldings and budding. The stroma is dense \& fibrous. The presence of atypia depends on the grade of hyperplasia.

ENDOMETRIAL CARCINOMA: This includes different grades \& classes of endometrial carcinomas with their unique diagnostic morphological features.

LEIOMYOMA: Most common benign tumor in the female, often missed by endometrial biopsy since it is located beneath the endometrium, it is common cause of vaginal bleeding. Bleedings are not associated with an organic cause known as dysfunctional uterine bleeding such as anovulatory period \& Luteal phase insufficiency [6].

Cases of dysfunctional uterine bleeding can be divided in two large categories, those associated with ovulation and the more numerous ones in which ovulation have not occurred. A hybrid group in which ovulatory and anovulatory cycles alternate is frequently seen in premenopausal patients [7,8]. In the ovulatory group, bleeding may occur because of an inadequate proliferative phase $\&$ irregular shedding of the endometrium, resulting from luteal phase insufficiency.

An anovulatory cycle can be recognized, at its earliest stage, by finding a proliferative endometrium at a time of the cycle when a secretory pattern would be expected.

\section{MATERIAL \& METHOD}

This study was carried out from Jan. 2019 to Dec. 2019 Hundred cases of endometrial biopsy for patient suffering from vaginal bleeding were selected $\&$ analyzed in this study, their age range from $18-55 \mathrm{yr}$.

All of the samples (Biopsies) that were taken from the patients by different gynecologist in private clinics were put in small containers which contains $10 \%$ formalin for preservation \& fixation of the biopsy. After fixation of the tissue by formalin for $24-48 \mathrm{hrs}$, representative pieces of tissue submitted for processing \& preparing of slides. The processing of the selected pieces of tissue includes the following steps; -

1) Dehydration; In dehydration, water is extracted from the fixed tissues by successive transfer through a graded series of ethanol and water mixtures, usually from $70 \%$ to $100 \%$ ethanol for $3 \mathrm{hrs}$. at $60^{\circ} \mathrm{C}$.

2) Clearing; - The ethanol is then replaced by an organic solvent (chloroform) miscible with both alcohol \& the embedding medium. for $2 \mathrm{hrs}$. at $60^{\circ} \mathrm{C}$.

3) Infiltration; - The fully cleared tissue is then placed in melted paraffin in an oven at $56^{\circ} \mathrm{C}$.

4) Embedding; The paraffin-infiltrated tissue is placed in a small mold with melted paraffin and allowed to harden.

5) Trimming \& sectioning: - The resulting paraffin block is trimmed to expose the tissue for sectioning (slicing) by the microtome. The paraffin sections are placed on glass slides and allowed to adhere, deparaffinized, and stained for light microscope study.

6) Staining by the ordinary stain, Hematoxylin \& Eosin.

7) Covered by DPX \& cover slide, \& become ready for examination.

All data concerning name, age, parity, obstetric history \& clinical presentations were collected from the patients or from the request forms sent by the gynecologists.

All data were analyzed according to the cause of bleeding, age $\&$ accuracy of endometrial sampling

\section{RESULTS}

Hundred cases of abnormal vaginal bleeding VB were selected \& endometrial biopsy was taken for evaluation; 5 biopsies were inadequate \& unsatisfactory for histopathological examinations; 6 biopsies were founded to be normal endometrium. About $70 \%$ of the cases of vaginal bleeding are due to organic lesion, while non-organic conditions comprise $19 \%$ of the causes only. Table 1 showing comprehensive information for the total 100 cases concerning causes of bleeding, incidence of each cause \& age group of the patient.

Table 1: incidence of $V B$ causes in relation to age groups

\begin{tabular}{|c|c|c|c|}
\hline $\begin{array}{c}\text { No. of } \\
\text { cases }\end{array}$ & $\begin{array}{c}\text { Histological study } \\
\text { findings }\end{array}$ & Incidence & $\begin{array}{c}\text { Age } \\
\text { group }\end{array}$ \\
\hline 5 & Inadequate biopsies & $5 \%$ & $40-50$ \\
\hline 6 & Normal Endometrium & $6 \%$ & $18-30$ \\
\hline 70 & Organic lesions & $70 \%$ & $40-55$ \\
\hline 19 & Non organic conditions & $19 \%$ & $25-50$ \\
\hline
\end{tabular}

$19 \%$ of the cases proved to be due to non-organic causes (functional) include anovulatory period $13 \%$ \& Luteal phase insufficiency $6 \%$, the other last $6 \%$ biopsies found to be normal. 
Table 2 organic lesions

\begin{tabular}{|c|c|c|}
\hline No. of cases & Type of lesion & Incidence \\
\hline 48 & Endometrial Hyperplasia & $48 \%$ \\
\hline 8 & Chronic endometritis & $8 \%$ \\
\hline 7 & Hydatidiform mole & $7 \%$ \\
\hline 7 & Endometrial polyp & $7 \%$ \\
\hline
\end{tabular}

The most frequent cause of vaginal bleeding was endometrial hyperplasia (48\%), it is commonly seen during the perimenopausal period. Other less common causes include variety of hormonal imbalance \& other organic lesions. As shown in table 3
Table 3: causes of bleeding

\begin{tabular}{|c|c|c|c|}
\hline $\begin{array}{c}\text { No. of } \\
\text { cases }\end{array}$ & Cause of bleeding & Incidence & $\begin{array}{c}\text { Range of } \\
\text { age }\end{array}$ \\
\hline 74 & $\begin{array}{c}\text { Endometrial } \\
\text { Hyperplasia }\end{array}$ & $48 \%$ & $35-55$ \\
\hline 13 & Anovulatory period & $13 \%$ & $40-45$ \\
\hline 8 & Chronic endometritis & $8 \%$ & $35-40$ \\
\hline 7 & Hydatidiform mole & $7 \%$ & $25-30$ \\
\hline 6 & $\begin{array}{c}\text { Luteal phase } \\
\text { insufficiency }\end{array}$ & $6 \%$ & $20-25$ \\
\hline 7 & Endometrial polyp & $7 \%$ & $40-50$ \\
\hline
\end{tabular}

Table 4 shows the relation of parity to the causes of vaginal bleeding and age groups.

\begin{tabular}{|c|c|c|c|}
\hline Parity & Organic lesion & Non organic conditions & Age \\
\hline nullipara & $\begin{array}{c}\text { Endometrial Hyperplasia } \\
\text { Chronic endometritis }\end{array}$ & Anovulatory period & $18-25$ \\
\hline \multirow{2}{*}{ primiparous } & $\begin{array}{c}\text { Endometrial Hyperplasia } \\
\text { Chronic endometritis } \\
\text { multiparous }\end{array}$ & $\begin{array}{c}\text { Andometrial Hyperplasia } \\
\text { Anovulatory period }\end{array}$ & $25-35$ \\
& Chronic endometritis & Luteal phase insufficiency \\
Anovulatory period & $35-50$ \\
\hline
\end{tabular}

\section{DISCUSSION}

Examination of specimens obtained on D\&C or endometrial biopsy is a continuous source of frustration for the pathologist. Sometimes, provided with inadequate clinical history or material taken at an unsuitable time of the menstrual cycle, or inadequate superficial biopsy making pathologist unable to recognize any abnormality. At the most, changes can be detected that only confirm what the gynecologist already knows-i.e., that the patient has an abnormal bleeding. These include the presence of fibrin clumps in the endometrial stroma (a finding not usually present in the normal menstrual endometrium) or the appearance of fragmented pieces with dense stromal cellularity (a process known as stromal crumbling) (Mahadevia, at, 2006). The increasing use of pipelle and other methods of Endometrial biopsy without general anesthesia has resulted in greater numbers of specimens with scant superficial sampling, resulting in problems in assessing adequacy and in interpreting artefactual changes, some of which appear more common with outpatient biopsies [8].

Traditionally, it has been recommended that the curetting or biopsy should be obtained on the twelfth postovulatory day or 2 days prior to the expected menstruation. However, recent studies suggest that an earlier biopsy taken on the seventh or eighth postovulatory day may be more informative (Castelbaum, 1994).

Abnormal uterine bleedings are either the result of an identifiable organic disease, including chronic infections, benign \& malignant lesions or bleeding not associated with an organic cause, call it dysfunctional uterine bleeding.
Dysfunctional uterine bleeding can be divided in two large groups, those associated with ovulation and the more frequent group with no ovulation has occurred. In the ovulatory group, bleeding may occur because of an inadequate proliferative phase $\&$ irregular shedding of the endometrium, which has been not recorded in this study, resulting from luteal phase insufficiency. An anovulatory cycle can be recognized, at its earliest stage, by finding a proliferative endometrium at a time of the cycle when a secretory pattern would be expected. Endometrial hyperplasia was the most frequent cause of vaginal bleeding as proved by this study. Lee KR, Scully RE said that endometrial hyperplasia is most commonly seen during the perimenopausal period. However, it can also be encountered in younger patients, even adolescent ones (McCluggage, 2006).

In this study the age ranging of endometrial hyperplasia is from 35-55yrs. Most commonly, the prolonged unremitting estrogen stimulation results in endometrial hyperplasia, as in the Stevin-Leventhal syndrome and in estrogen secreting ovarian neoplasm .

The distinction between an extreme case of hyperplasia and a well-differentiated adenocarcinoma is very difficult, largely because of the fact that endometrial hyperplasia and carcinoma represent different points in a disease continuum at the morphologic, ultrastructural, biochemical, immunocytochemical, and cytodynamic levels. Microscopic features favoring carcinoma include marked pleomorphism with loss of polarity, complex ramification of disorderly arranged glands, extensive papillary formations, confluent glandular pattern with a solid or cribriform appearance, and desmoplastic reaction (Mahadevia, at, 2006). 
Most cases of endometrial carcinoma are preceded by a stage of hyperplasia. This is especially true in the younger woman and/or in cases of well-differentiated endometrioid adenocarcinoma. In the classic series of Hertig and Sommers [5], all patients with endometrial adenocarcinoma who had adequate material from curettage examined 15 years or less before the development of adenocarcinoma had an abnormal endometrial pattern.

Overall, relatively few patients with hyperplasia will subsequently develop cancer. Therefore, the mere presence of hyperplasia is not a basis for hysterectomy (Mahadevia, at, 2006),

The more severe the hyperplasia, the more likely it is to be followed by carcinoma. This is particularly true in regard to the cytological changes, even if these assume even greater significance when coupled with architectural changes. This correlation has been demonstrated both using conventional morphologic evaluation and with morphometric techniques (Mahadevia, at, 2006).

In the case of simple hyperplasia (often accompanied by cystic changes) the risk of developing endometrial carcinoma is very small.[6]

Atrophic endometrium is common cause of vaginal bleeding in postmenopausal women, due to degenerative changes in the uterine blood vessels2, has not reported in this study.

\section{CONCLUSION}

Endometrial Biopsy is an outpatient procedure, low cost, without general anesthesia. The incidence of haemorrhage, infection \& perforation are less common than with D\&C.

It provides only a sample of endometrium, so a localize small lesion such as carcinoma, polyps \& subcutaneous myoma may be missed. Nevertheless, it is very useful procedure to exclude endometrial hyperplasia \& carcinoma.

It is adequate \& acceptable screening procedure in women under 40yr.Old.

Biopsy must be taken at the appropriate time of the menstrual cycle to avoid inconclusive \& frustrated results.
I suggest that an earlier biopsy taken on the seventh or eighth postovulatory day may be more informative than the traditional way, that the curetting or biopsy should be obtained on the twelfth postovulatory day or 2 days prior to the expected menstruation.

In this study, 3 cases reveal normal endometrium, this may due to ;

1) Cause of bleeding was systemic disease \& has no relation to the endometrium.

2) 2 .Material taken at an inappropriate moment of the menstrual cycle.

3) The cause of bleeding was due to localize pathology such as polyp, submucosal myoma, adenomayosis, or small carcinoma, those lesions may be missed by the gynecologist during biopsy taking which is one of the disadvantages of this technique.

Endometrial hyperplasia, which is the common cause of abnormal vaginal bleeding, is most commonly seen during the perimenopausal period. However, its can also encountered in younger patient .

Carcinoma of the endometrium has not been reported in this study this may be due to- ;

1) Its low incidence in Iraqi peoples, especially in childbearing age that this study based upon.

2) It is difficult to diagnose endometrial carcinoma, especially when it is localized, by endometrial biopsy because the biopsy may be taken from normal area $\&$ the abnormal lesion was missed.

So sufficient, multiple pieces from different sites of the endometrium must be taken for conclusive \& informative histopathological report.

Four cases of hydatidiform mole were detected, two of them because of incomplete evacuation of the placenta, $\&$ other two because of incomplete abortion \& inadequate evacuation of the uterus.

Atrophic endometrium is common cause of postmenopausal bleeding has not been reported in this study because it is out of age scope of our patient.

\section{REFERENCES}

[1] Goldblum JR, Lamps LW, Mckenney JK, M. JL. (2018). Rosai and Ackerman's Surgical Pathology - 2 Volume Set. ELSEVIER (pp. 1530-1631). Retrieved from https://doi.org/10.1016/B978-0-323-26339-9.00037-8

[2] Jiménez-Ayala, M., \& Portillo, B. J. A. (2008). Endometrial adenocarcinoma prevention and early diagnosis. Monographs in Clinical Cytology, 17, 1-87. https://doi.org/10.1159/000325638

[3] Mahadevia, P. S., Tanaka, K., \& Fineberg, S. (2006). Rosai and Ackerman's surgical pathology, 9th edition author: Juan Rosai Mosby, Edinburgh, 2004. Diagnostic Cytopathology, 34(5), 382-383. https://doi.org/10.1002/dc.20292 
[4] McCluggage, W. G. (2006, August). My approach to the interpretation of endometrial biopsies and curettings. Journal of Clinical Pathology. https://doi.org/10.1136/jcp.2005.029702

[5] Schöniger, S., \& Schoon, H. A. (2020, April 1). The healthy and diseased equine endometrium: A review of morphological features and molecular analyses. Animals. MDPI AG. https://doi.org/10.3390/ani10040625

[6] Schickedanz, A. C., Kalro, B. N., \& Berga, S. L. (2008). Bleeding Problems in Midlife. The Global Library of Women's Medicine. https://doi.org/10.3843/glowm.10297

[7] Mishra, D., \& Sultan, S. (2017). FIGO's PALM-COEIN Classification of Abnormal Uterine Bleeding: A Clinicohistopathological Correlation in Indian Setting. Journal of Obstetrics and Gynecology of India, 67(2), 119-125. https://doi.org/10.1007/s13224-016-0925-8

[8] Feldman, A. L., \& Yi, E. S. (2012). Rosai and Ackerman's Surgical Pathology. JAMA, 307(2), 201. https://doi.org/10.1001/jama.2011.1993 